\title{
Review: antibiotics modestly increase remission rates in acute bacterial conjunctivitis
}

Sheikh A, Hurwitz B. Topical antibiotics for acute bacterial conjunctivitis: a systematic review. Br J Gen Pract 2001 Jun 1;51:473-7.

Sheikh A, Hurwitz B, Cave J. Antibiotics for acute bacterial conjunctivitis. Cochrane Database Syst Rev 2001;(3):CD001211 (latest version 27 Oct 1999).

\section{QUESTION: In patients with acute bacterial conjunctivitis, does antibiotic treatment increase clinical remission?}

\section{Data sources}

Studies were identified by searching Medline, Science Citation Index, the Cochrane Eyes and Vision Group Register, and the Cochrane Controlled Trials Register (to September 1998); scanning bibliographies of relevant studies; and contacting authors and pharmaceutical companies.

\section{Study selection}

Studies were selected if they were randomised, double blind, controlled trials in which any type of antibiotic treatment (topical, systemic, or a combination) was compared with placebo in patients with acute bacterial conjunctivitis.

\section{Data extraction}

Both reviewers independently assessed the quality of studies. 1 reviewer extracted data on participants, disease definition, interventions, and outcomes. Outcomes were clinical remission (defined as clinical cure or clinically significant improvement) and microbiological remission (defined as pathogen eradication or reduction). The other reviewer checked the accuracy of data extraction.

\section{Main results}

3 studies (527 patients) met the selection criteria. 1 study included children ( 1 mo to $18 \mathrm{y}$ of age), 1 included adults, and 1 did not specify the age of patients. Antibiotic treatment included polymixin $10000 \mathrm{U} / \mathrm{g}$ plus bacitracin $500 \mathrm{U} / \mathrm{g}$, and $0.3 \%$ norfloxacin plus $0.0025 \%$ benzalkonium chloride preservative. 1 study presented combined results for 2 studies that compared ciprofloxacin with placebo and ciprofloxacin with tobramycin. Follow up ranged from 2 to 10 days. Pooled results showed that antibiotics increased microbiological and clinical remission rates at 2 to 5 days and at 6 to 10 days (table). No serious adverse events were reported in the antibiotic or placebo groups.

\section{Conclusion}

In patients with acute bacterial conjunctivitis, most remit spontaneously, but antibiotic treatment further increases clinical and microbiological remission rates.

\section{COMMENTARY}

Acute bacterial conjunctivitis is a common minor illness. It is self limiting but is usually treated pragmatically with topical antibiotics in an attempt to shorten the illness and reduce complications and infectivity. Eye swabs are rarely done in clinical practice because of time considerations and expense. Discrimination of bacterial from viral conjunctivitis on clinical grounds is difficult: $50 \%$ of cases of presumed bacterial conjunctivitis diagnosed clinically by ophthalmologists in 1 study did not have an underlying bacterial

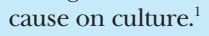

Recently, clinicians have been encouraged to reduce the prescribing of antibiotics for other minor self limiting illnesses (ie, sore throat and otitis media) because of problems with antibiotic resistance.

The review by Sheikh and Hurwitz used rigorous methods to summarise the limited evidence on acute bacterial conjunctivitis. The trials are from secondary care and thus may not be directly applicable to primary care settings. All the trials used microbiologically confirmed cases, which means that the number needed to treat using clinical diagnosis of patients will probably be substantially higher.

Although the review shows improved clinical and microbiological remission rates with antibiotics, it must be remembered that this condition is self limiting. Symptoms are usually mild, and the review shows that $64 \%$ of patients are cured at day 2 to 5 without treatment. No serious adverse effects were seen in these studies, which suggests that sightthreatening complications are rare. The effect of a quicker cure in reducing secondary cases of conjunctivitis has not been assessed.

Further trials are needed to clarify whether it is appropriate to prescribe antibiotics for all patients to achieve a few days of reduction in symptoms in a minority of patients. In the meantime, as discussed by the authors, it might be worth considering a delayed prescription strategy (ie, prescribing only for those cases that have not resolved by day 5 ).

Hazel Everitt, MB, ChB University of Southampton Southampton, UK

1 Mahajan VM. Acute bacterial infections of the eye: their aetiology and treatment. BrJ Ophthalmol 1983:67:191-4.

Antibiotics $(A B)$ v placebo for acute bacterial conjunctivitis*

\begin{tabular}{|c|c|c|c|c|c|c|}
\hline \multirow[b]{2}{*}{ Outcomes } & \multirow[b]{2}{*}{ Follow up } & \multirow[b]{2}{*}{ Number of studies } & \multicolumn{2}{|c|}{ Weighted event rates } & \multirow[b]{2}{*}{ RBI $(95 \%$ Cl) } & \multirow[b]{2}{*}{ NNT (Cl) } \\
\hline & & & $A B$ & Placebo & & \\
\hline \multirow[t]{2}{*}{ Clinical remission } & 2 to 5 days & 2 & $83 \%$ & $64 \%$ & $31 \%$ (16 to 49 ) & 6 (4 to 9 ) \\
\hline & 6 to 10 days & 1 & $91 \% \dagger$ & $72 \% \dagger$ & $27 \%(0.9$ to 69$)$ & 6 (3 to 173 ) \\
\hline \multirow[t]{2}{*}{ Microbiological remission } & 2 to 5 days & 3 & $77 \%$ & $44 \%$ & $71 \%$ (41 to 108 ) & 4 (3 to 5 ) \\
\hline & 6 to 10 days & 2 & $78 \%$ & $46 \%$ & $71 \%$ (35 to 117 ) & 4 (3 to 5 ) \\
\hline
\end{tabular}

*Abbreviations defined in glossary; RBI, NNT, and $\mathrm{Cl}$ calculated from data in article using a fixed effects model. †Unweighted event rates. 